\title{
Newly Diagnosed Idiopathic Liver Abscess: Colonoscopy Required!
}

\author{
Priyanka Makkar ${ }^{\mathrm{a}}$, Tagore Sunkara ${ }^{\mathrm{b}, \mathrm{c}}$, Manan Jhaveria, Judith Berger ${ }^{\mathrm{a}}$, \\ Vinaya Gaduputia , Jay P. Babich ${ }^{\mathrm{a}}$
}

\begin{abstract}
Liver abscess is the most common type of visceral abscess reported in the United States. Biliary tract disease is the most common cause of the development of liver abscess. In the last decade, many cases of liver abscesses silently manifesting as colon cancer have been reported in East Asian countries. We herein describe a case of an immunocompetent man who immigrated from East Africa to Unites States and presented with a suspicion of colon mass with metastasis to the liver, and who was later diagnosed to have a colonic malignancy with a concomitant liver abscess. Our aim was to make clinicians aware of the importance of ruling out occult colonic malignancy in patients with idiopathic liver abscess.
\end{abstract}

Keywords: Liver abscess; Colon cancer; Malignancy of colon; Liver metastasis; Colonoscopy

\section{Introduction}

Liver abscess is the most common type of visceral abscess reported in the United States [1]. On the other hand, colon cancer is the third most common cancer in men and second most common cancer diagnosed in women globally [2]. In a retrospective analysis done in Taiwan, there was a fourfold increase of gastrointestinal malignancies noted in patients with liver abscess [3]. These abscesses are more commonly found in immunodeficient patients, including those with underlying malignancies, poorly controlled diabetes mellitus and those receiving chemotherapy, immunosuppressive therapy [4].

Manuscript submitted September 3, 2017, accepted September 25, 2017

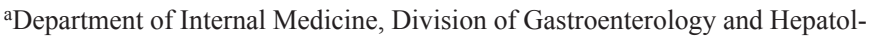
ogy, Division of Infectious Diseases, SBH Health System, 4422 Third Ave, Bronx, NY 10457, USA

bivision of Gastroenterology and Hepatology, The Brooklyn Hospital Center, Clinical Affiliate of The Mount Sinai Hospital, 121 Dekalb Ave, Brooklyn, NY 11201, USA

${ }^{\mathrm{c} C o r r e s p o n d i n g ~ A u t h o r: ~ T a g o r e ~ S u n k a r a, ~ D i v i s i o n ~ o f ~ G a s t r o e n t e r o l o g y ~ a n d ~}$ Hepatology, The Brooklyn Hospital Center, Clinical Affiliate of The Mount Sinai Hospital, 121 Dekalb Avenue, Brooklyn, NY 11201, USA.

Email: tagoresunkara@hotmail.com

doi: https://doi.org/10.14740/jocmr3184w
We here report a case of a patient who immigrated from Africa to United States and presented with a suspicion of a colon mass with metastasis to the liver, which was later diagnosed to be a liver abscess.

\section{Case Report}

A 45-year-old African man from Senegal presented with a 3-day history of epigastric abdominal discomfort associated with subjective fevers, malaise and weight loss. His other medical conditions included bronchial asthma, peptic ulcer disease and newly diagnosed diabetes mellitus with an $\mathrm{HbAlc}$ of $7 \%$. Initial laboratory data were significant for leucocyte count of $11.8 \times 10^{3} / \mu \mathrm{L}$ with a left shift and moderate transaminitis (aspartate aminotransferase of $67 \mathrm{U} / \mathrm{L}$ and alanine aminotransferase of $105 \mathrm{U} / \mathrm{L}$ ). A computed tomography (CT) scan of abdomen and pelvis with contrast demonstrated a $7.5 \times 7.0 \mathrm{~cm}$ mass in the left hepatic lobe with possible areas of central necrosis and sigmoid wall thickening with focal irregularity suspicious for a mass lesion (Fig. 1).

Tumors markers including alpha fetoprotein (AFP) and carcinoembryonic antigen (CEA) were found to be negative. Patient also tested negative for HIV and hepatitis $\mathrm{C}$ and was found to be immune to hepatitis $\mathrm{B}$. Considering the sigmoid wall thickening on imaging, a diagnostic colonoscopy was performed which revealed a $5 \mathrm{~cm}$ pedunculated polyp in the sigmoid colon (Fig. 2), and four polyps in the cecum each measuring $0.4 \mathrm{~cm}$. These polyps were resected with hot snare polypectomy. The

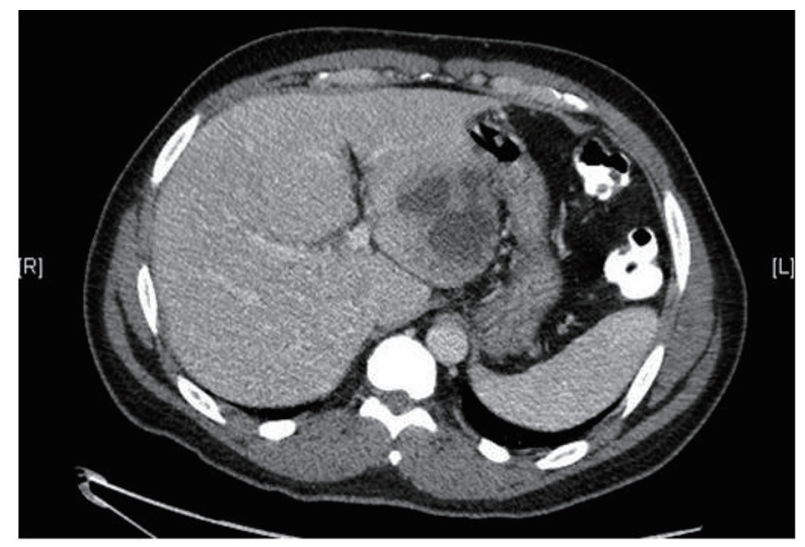

Figure 1. CT of abdomen/pelvis with contrast showing $7.5 \times 7.0 \mathrm{~cm}$ multilobulated complex mass in the left lobe of the liver. 


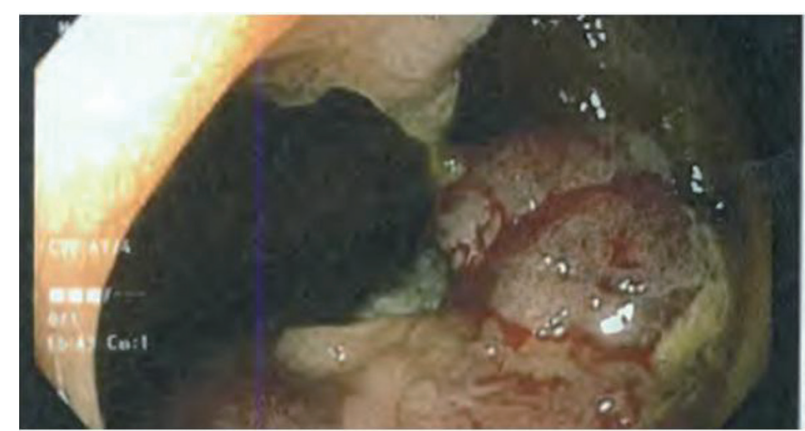

Figure 2. Diagnostic colonoscopy revealing a $5 \mathrm{~cm}$ pedunculated polyp in the sigmoid colon.

pathology of the sigmoid polyp was consistent with a moderately differentiated invasive adenocarcinoma without lymphatic or vascular invasion and with clear margins (Fig. 3). Pathology of the cecal polyps was consistent with tubulo-villous adenoma.

Patient continued to have persistent febrile episodes during his hospitalization. Patient underwent liver mass biopsy which revealed a hepatic abscess (Fig. 4). Cultures from the abscess were positive for Klebisella pneumoniae. Patient was started on ceftriaxone and metronidazole with resolution of fever and discharged on ciprofloxacin and metronidazole to complete a 45-day course. A CT scan of the abdomen/pelvis (Fig. 5) obtained on the 21st day after initiation of antibiotics showed an interval decrease in size of the dominant lowattenuation lesion in the posterior left liver lobe. Patient successfully underwent laparoscopic lower anterior resection of the sigmoid colon. Pathology demonstrated a residual tubular adenoma with unremarkable margins and lymph nodes.

\section{Discussion}

Various etiologies and pathogenesis of liver abscess have been identified in the past [4]. Eighty percent of the liver abscesses in the United States are pyogenic [5]. Traditionally, appendi-

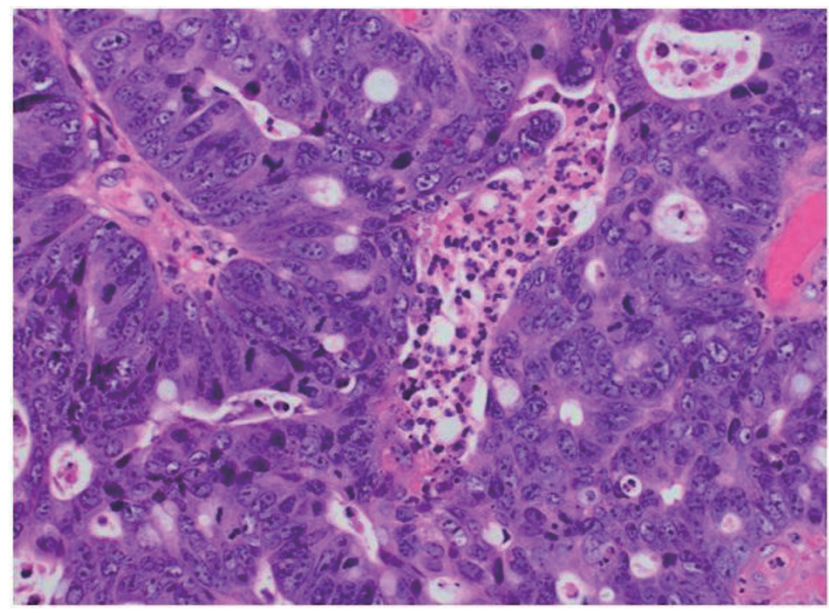

Figure 3. Pathology of the sigmoid colon polyp showing moderately differentiated invasive adenocarcinoma.

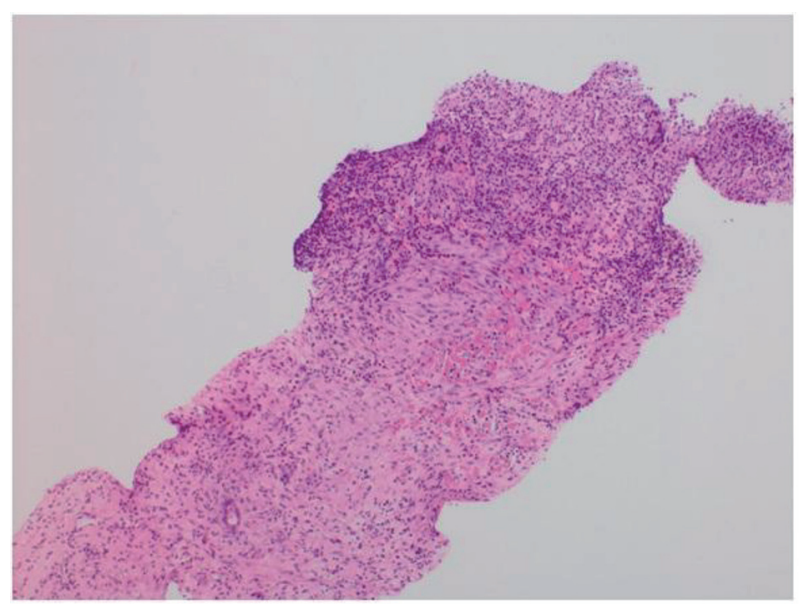

Figure 4. Liver biopsy showing granulation tissue surrounded by fibrotic cap; consistent with an abscess.

citis was reported as the most common cause of liver abscess. However, its incidence now has dropped down to $10 \%$. Biliary tract disease is now the most common cause of liver abscess. Common manifestations of colorectal cancer include weight loss, malaise, change in stool color and/or caliber, hematochezia, and generalized abdominal pain [4]. Pyogenic liver abscess is regarded as a possible heralding sign of an underlying colorectal cancer [6]. In the last decade, many cases of liver abscesses silently manifesting as colon cancer have been reported in the East Asian countries [6, 7].

Demographic features from the reported cases of colon cancer with concomitant liver abscess indicate that the average age of diagnosis is 64.4 years and men are 1.5 times more likely affected [8]. Other common features were the diagnosis of diabetes mellitus type 2 [9], sigmoid colon as the most common site of tumor identification and Klebsiella pneumoniae as the most common pathogen isolated from the abscess in cases described from the eastern Asian countries [10]. The proposed pathogenesis for the liver abscess formation is the destruction of the colonic mucosal barrier and repeated bacterial translocation [10].

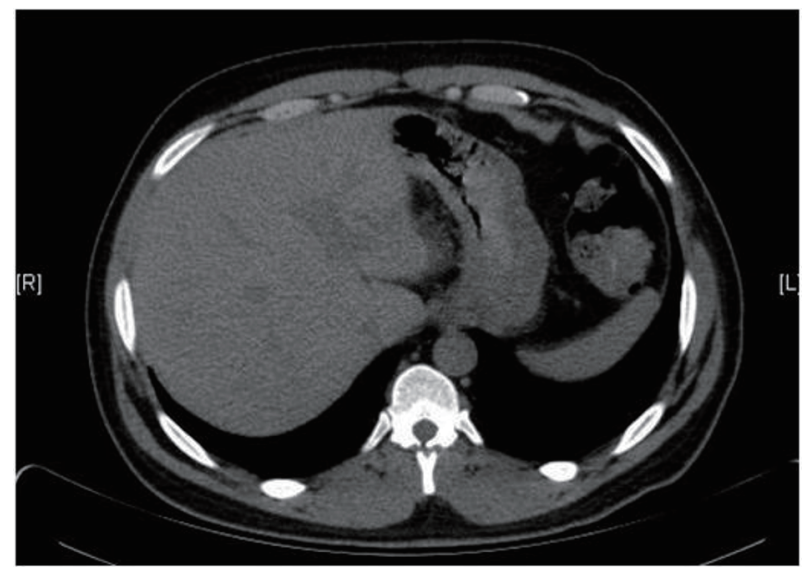

Figure 5. CT of abdomen/pelvis with contrast after 3 weeks of antibiotic therapy showing an interval decrease in size of the left lobe hepatic mass, now measuring $3.6 \times 3.0 \mathrm{~cm}$. 
In our case, abdominal pain and malaise were the presenting symptoms in a 45-year-old man with fairly well controlled diabetes mellitus (HbA1c 7\%). CT of the abdomen and pelvis demonstrated a multilobulated liver mass and a thickened sigmoid colon. Initially, it was suspected that the liver mass was probably a metastatic focus of occult colon cancer. Colonoscopy confirmed adenocarcinoma of the sigmoid colon but persistent fever in the patient, leading the team to perform a biopsy of the liver mass which was ultimately found to be an abscess.

In conclusion, a practicing clinician must be keenly aware that in patients with liver abscesses in whom common etiologies such as biliary tract diseases are ruled out, a colonoscopy must be performed to rule out an occult colonic lesion.

\section{Author Contributions}

Conception and design: Priyanka Makkar, Tagore Sunkara, Manan Jhaveri, Judith Berger, Vinaya Gaduputi, and Jay P. Babich. Drafting of the article: Tagore Sunkara, Priyanka Makkar, Manan Jhaveri, Judith Berger, Vinaya Gaduputi, and Jay P. Babich. Critical revision of the article for important intellectual content: Tagore Sunkara, Priyanka Makkar, and Vinaya Gaduputi. Final approval of the article: Tagore Sunkara, Priyanka Makkar, Manan Jhaveri, Judith Berger, Vinaya Gaduputi, and Jay P. Babich.

\section{Disclosures}

It was presented as a poster at American College of Gastroenterology in Hawaii in 2015.

\section{Consent}

Informed consent for participation was obtained from this patient.

\section{Conflict of Interest}

None of the authors have any financial conflict of interest.

\section{References}

1. Altemeier WA, Culbertson WR, Fullen WD, Shook CD. Intra-abdominal abscesses. Am J Surg. 1973;125(1):7079.

2. Torre LA, Bray F, Siegel RL, Ferlay J, Lortet-Tieulent J, Jemal A. Global cancer statistics, 2012. CA Cancer J Clin. 2015;65(2):87-108.

3. Lai HC, Lin CC, Cheng KS, Kao JT, Chou JW, Peng $\mathrm{CY}$, Lai SW, et al. Increased incidence of gastrointestinal cancers among patients with pyogenic liver abscess: a population-based cohort study. Gastroenterology. 2014;146(1):129-137 e121.

4. Lopez-Cano Gomez M, Laguna Del Estal P, Garcia Montero P, Gil Navarro M, Castaneda Pastor A. [Pyogenic liver abscess: clinical presentation and predictors of unfavorable outcome]. Gastroenterol Hepatol. 2012;35(4):229-235.

5. Othman N, Mohamed Z, Yahya MM, Leow VM, Lim BH, Noordin R. Entamoeba histolytica antigenic protein detected in pus aspirates from patients with amoebic liver abscess. Exp Parasitol. 2013;134(4):504-510.

6. Fernandez Ruiz M, Guerra Vales JM, Castelbon Fernandez FJ, Llenas Garcia J. [Pyogenic liver abscess as presenting manifestation of silent colon adenocarcinoma]. Rev Esp Enferm Dig. 2007;99(5):303-305.

7. Giuliani A, Caporale A, Demoro M, Scimo M, Galati F, Galati G. Silent colon carcinoma presenting as a hepatic abscess. Tumori. 2007;93(6):616-618.

8. Thomas CC, Richards TB, Plescia M, Wong FL, Ballard R, Levin TR, Calonge BN, et al. CDC Grand Rounds: the future of cancer screening. MMWR Morb Mortal Wkly Rep. 2015;64(12):324-327.

9. Hsu WH, Yu FJ, Chuang CH, Chen CF, Lee CT, Lu CY. Occult colon cancer in a patient with diabetes and recurrent Klebsiella pneumoniae liver abscess. Kaohsiung $\mathrm{J}$ Med Sci. 2009;25(2):98-103.

10. Huang WK, Chang JW, See LC, Tu HT, Chen JS, Liaw $\mathrm{CC}$, Lin YC, et al. Higher rate of colorectal cancer among patients with pyogenic liver abscess with Klebsiella pneumoniae than those without: an 11-year follow-up study. Colorectal Dis. 2012;14(12):e794-801. 